Supplement of Earth Syst. Dynam., 11, 903-923, 2020

https://doi.org/10.5194/esd-11-903-2020-supplement

(c) Author(s) 2020. This work is distributed under

the Creative Commons Attribution 4.0 License.

Earth System
Dynamics

(c) (i)

Supplement of

\title{
The synergistic impact of ENSO and IOD on Indian summer monsoon rainfall in observations and climate simulations - an information theory perspective
}

Praveen Kumar Pothapakula et al.

Correspondence to: Praveen Kumar Pothapakula (pothapakula@iau.uni-frankfurt.de)

The copyright of individual parts of the supplement might differ from the CC BY 4.0 License. 

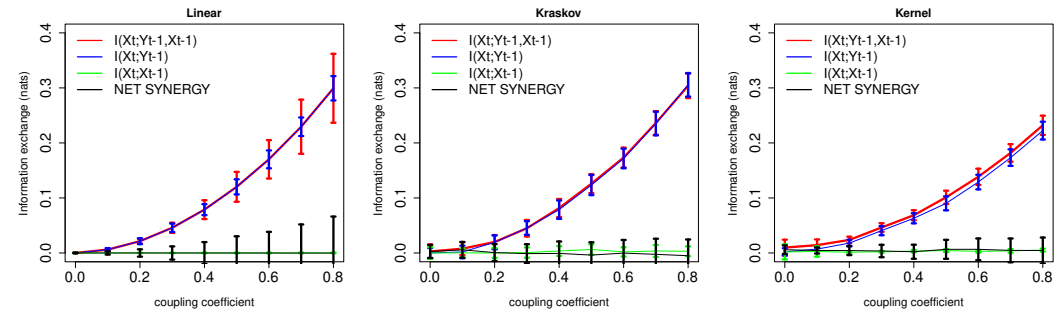

Fig. S1 Information exchange in nats from two-source (red line), single source (green and blue lines), and net synergy (black line) to target for Linear, Kraskov and Kernel estimators. The error bars represents two standard deviations of the 100 permuted samples.
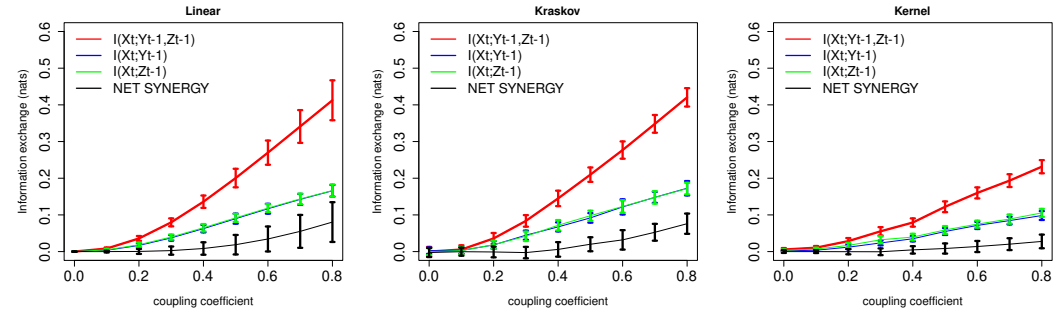

Fig. S2 Information exchange in nats from two-source (red line), single source (green and blue lines), net synergy (black line) to target for Linear, Kraskov and Kernel estimators. The error bars represents two standard deviations of the 100 permuted samples. 

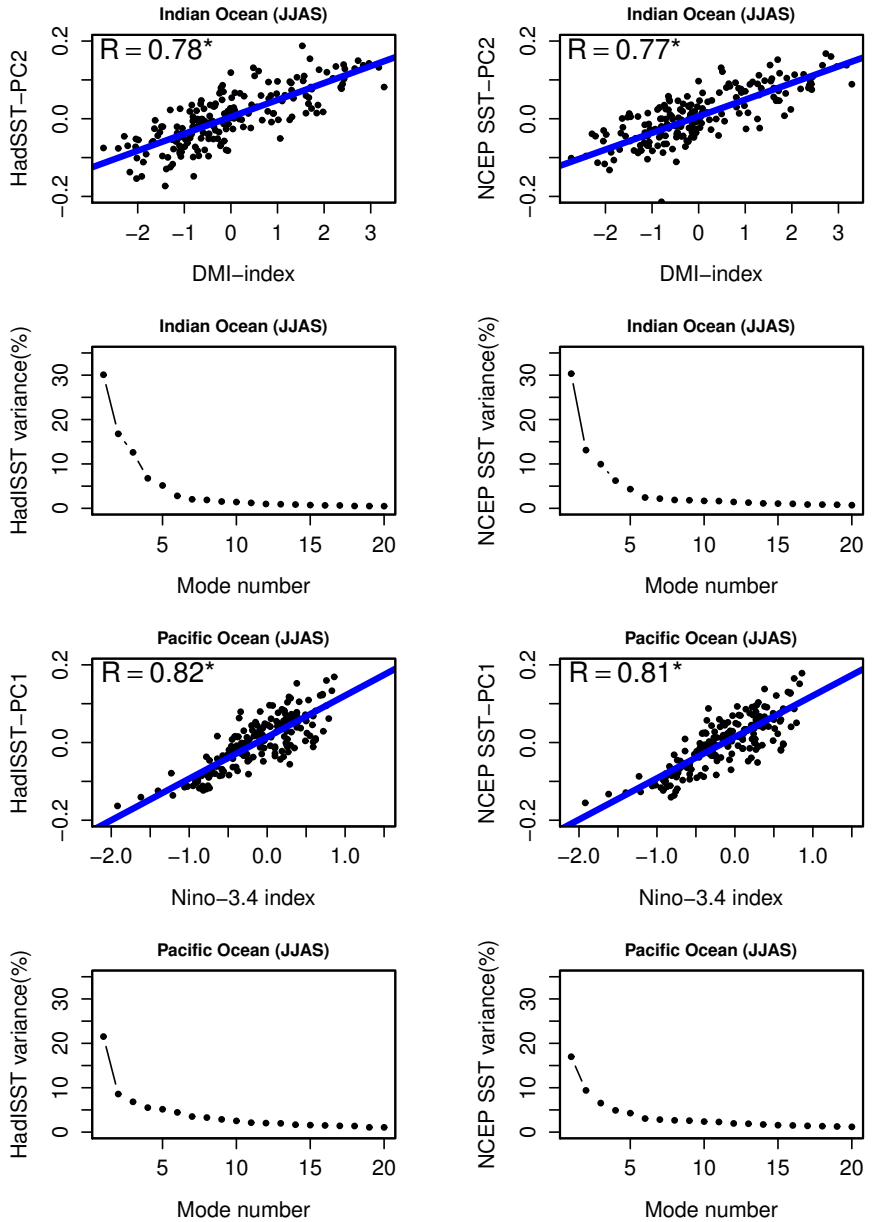

Fig. S3 Regressions of PCs obtained from their respective EOFs over the Indian and Pacific Oceans with the observed IOD and Niño 3.4 Index and their associated percentage contribution to the total variance for HadISST and NCEP reanalysis SST data sets for JJAS 

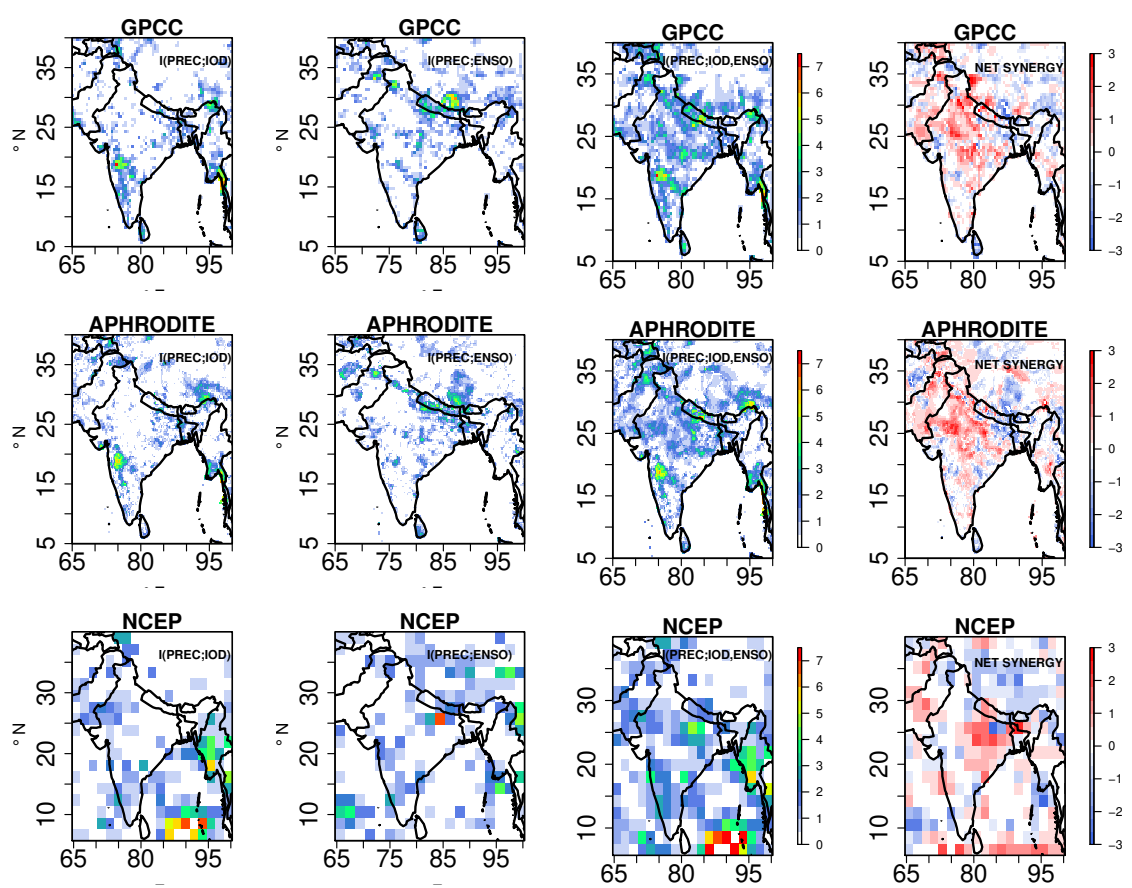

Fig. S4 Information exchange from $I(P R E C ; I O D), I(P R E C ; E N S O)$, two-source information exchange I $(P R E C ; E N S O, I O D)$ and NET SYNERGY $\times 10^{-2}$ nats for observational data sets GPCC, APHRODITE and NCEP reanalysis with Kraskov estimator for JJAS. Only significant values at $95 \%$ confidence intervals are plotted. 

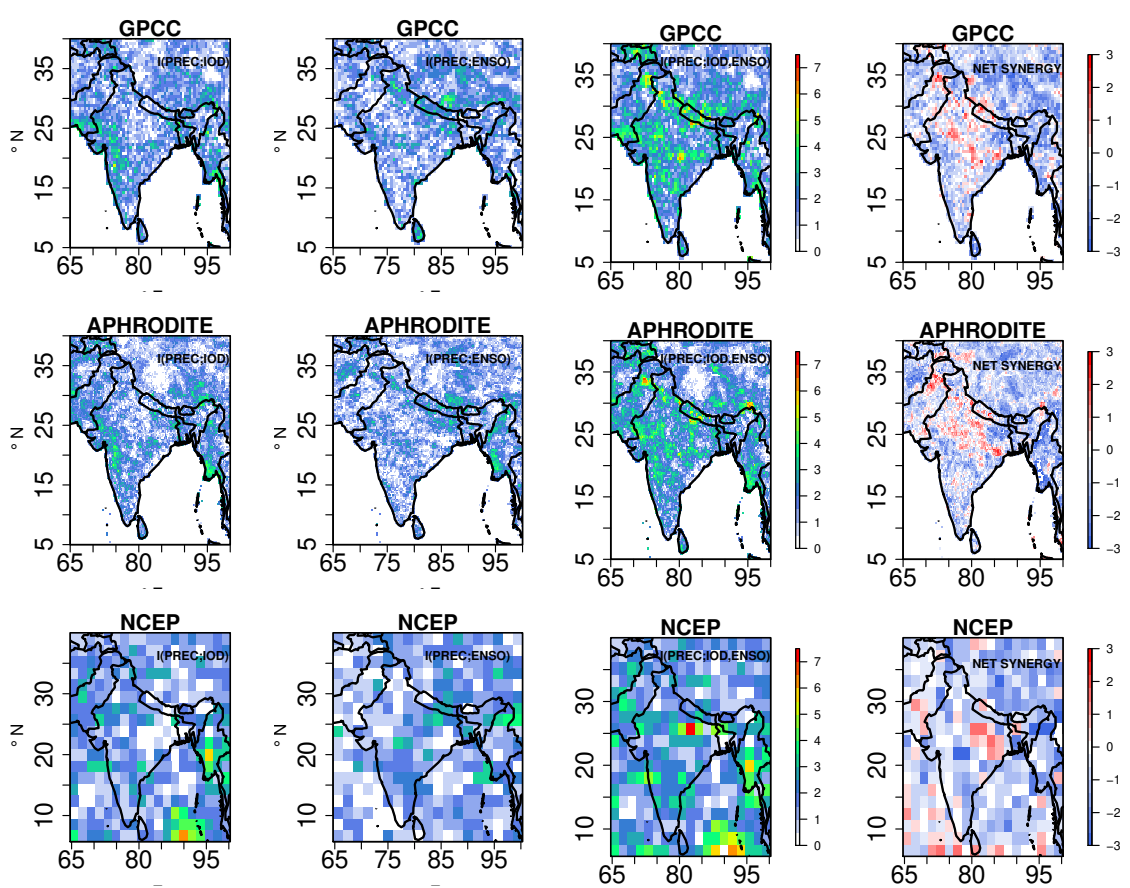

Fig. S5 Information exchange from $I(P R E C ; I O D), I(P R E C ; E N S O)$, two-source information exchange $I(P R E C ; E N S O, I O D)$ and NET SYNERGY $\times 10^{-2}$ nats for observational data sets GPCC, APHRODITE and NCEP reanalysis with Kernel estimator for JJAS. Only significant values at $95 \%$ confidence intervals are plotted.
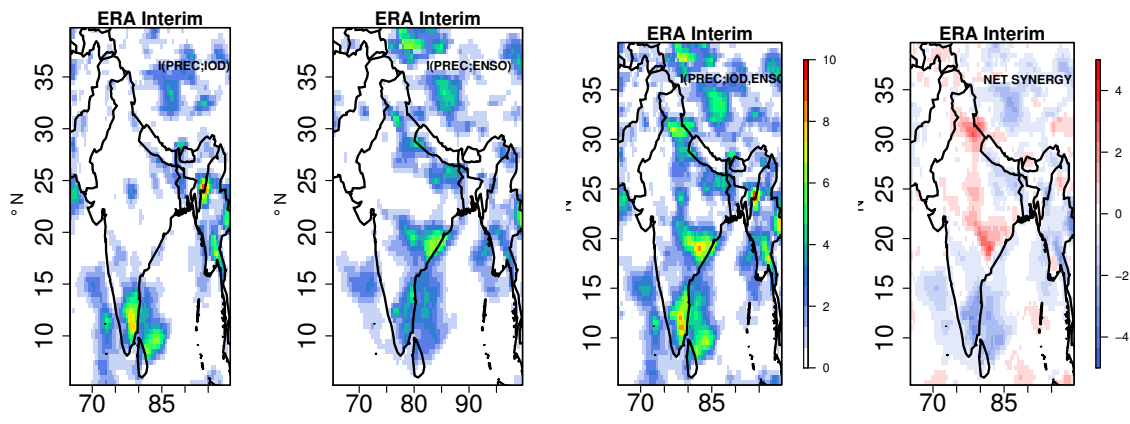

Fig. S6 Information exchange from $I(P R E C ; I O D), I(P R E C ; E N S O)$, two-source information exchange I $P R E C ; E N S O, I O D)$ and NET SYNERGY $\times 10^{-2}$ nats for observational data set ERA Interim reanalysis (1980-2005) for JJAS. Only significant values at 95\% confidence intervals are plotted. 

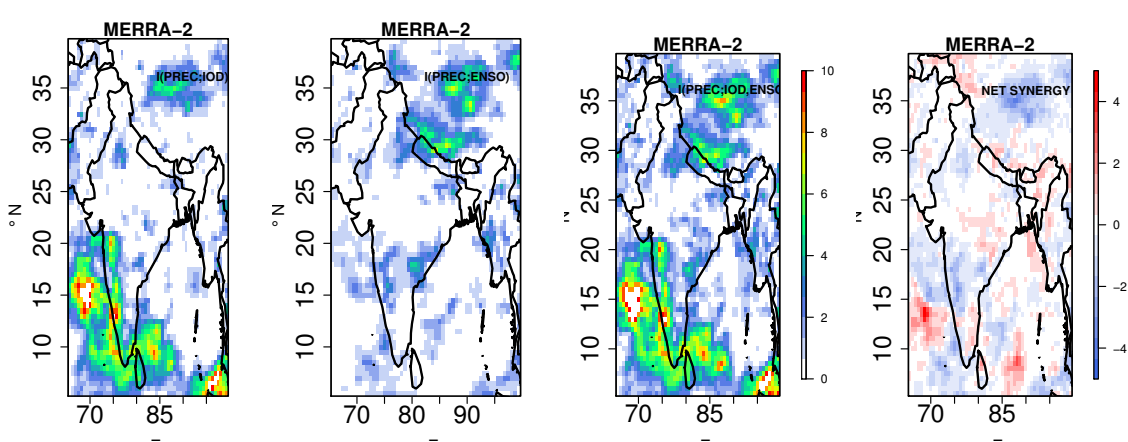

Fig. S7 Information exchange from $I(P R E C ; I O D), I(P R E C ; E N S O)$, two-source information exchange $I(P R E C ; E N S O, I O D)$ and NET SYNERGY $\times 10^{-2}$ nats for observational data set MERRA-2 reanalysis (1980-2005) for JJAS. Only significant values at $95 \%$ confidence intervals are plotted.
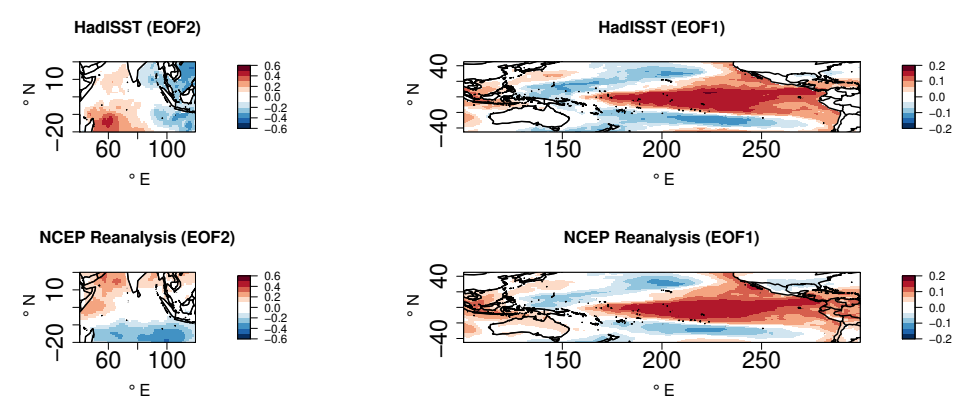

Fig. S8 EOF2 patterns of SST anomalies (DJFM) in the Indian ocean and EOF1 patterns in the Pacific ocean for observed HadISST and NCEP reanalysis.
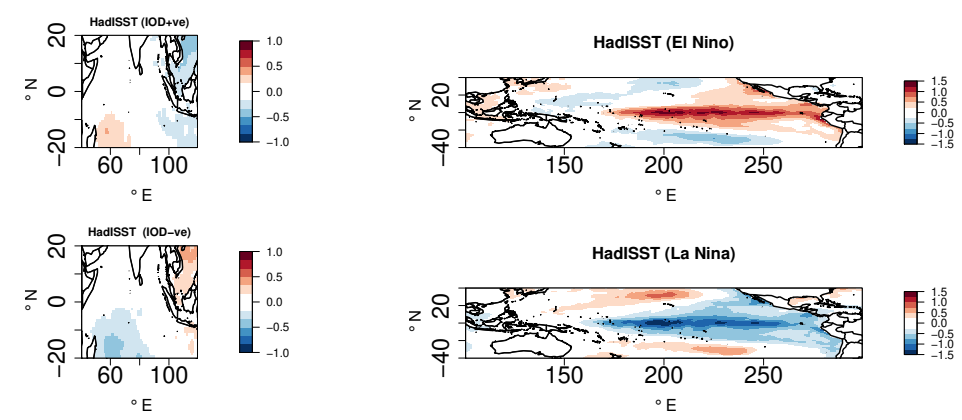

Fig. S9 SST composites (DJFM) in the Indian ocean and the Pacific ocean for observed HadISST. 

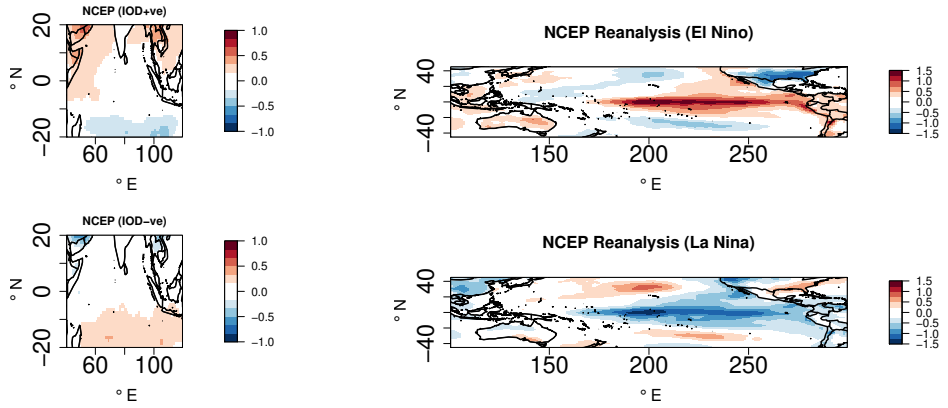

Fig. S10 SST composites (DJFM) in the Indian ocean and the Pacific ocean for observed NCEP reanalysis. 

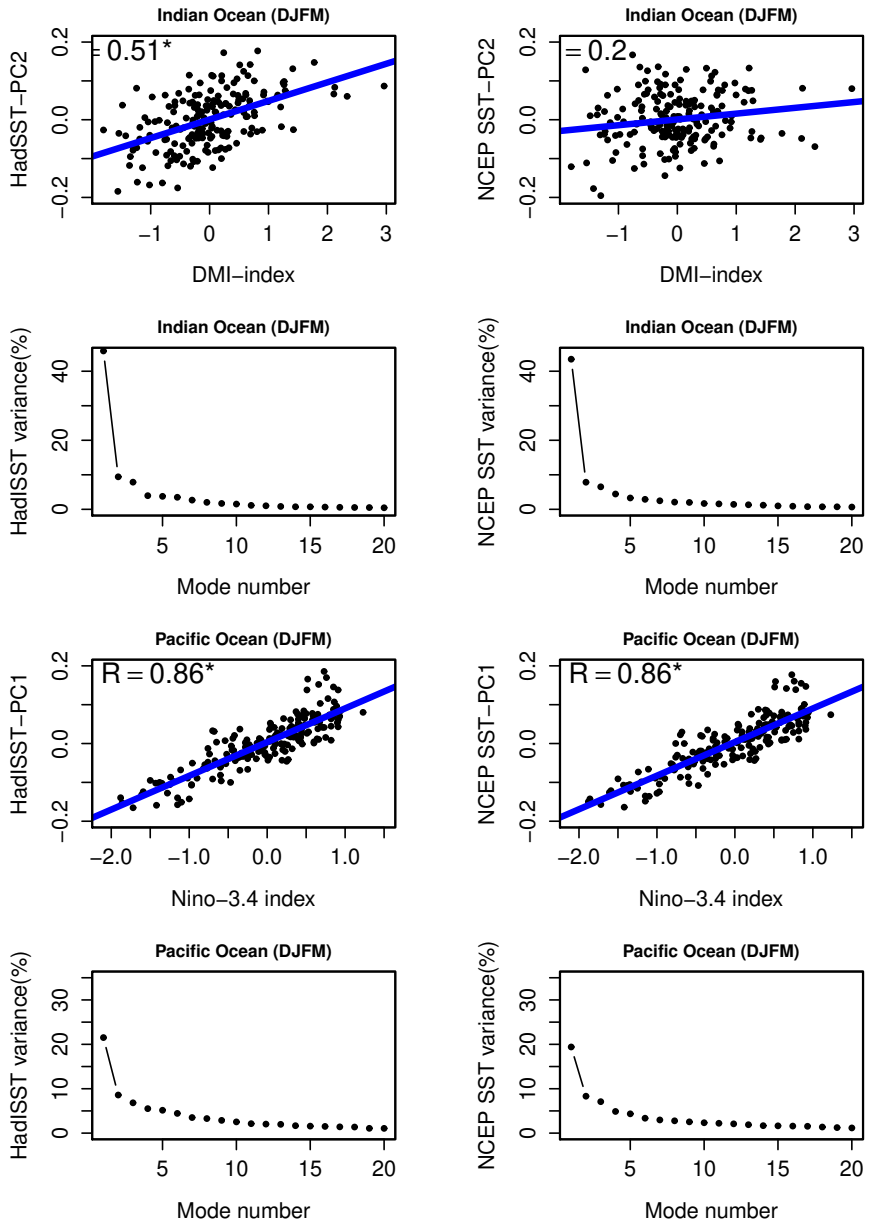

Fig. S11 Regressions of PCs obtained from their respective EOFs over the Indian and Pacific Oceans with the observed IOD and Niño 3.4 Index and their associated percentage contribution to the total variance for HadISST and NCEP reanalysis SST data sets for DJFM. 

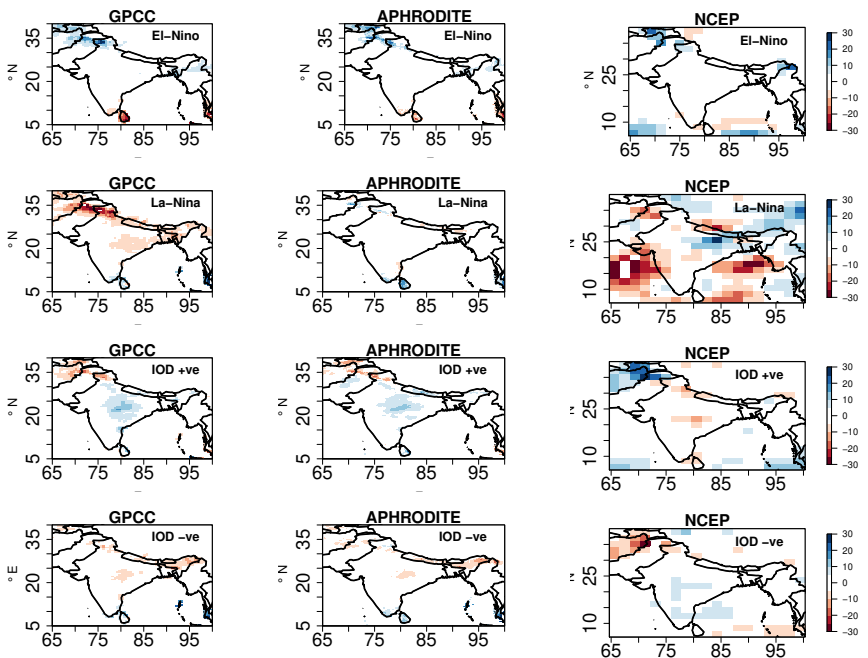

Fig. S12 Total precipitation anomaly ( $\mathrm{mm} /$ month) composites (DJFM) over the Indian subcontinent for El-Niño, La-Niña, positive IOD and negative IOD events observed in GPCC, APHRODITE and NCEP reanalysis data sets for the period of 1951-2005
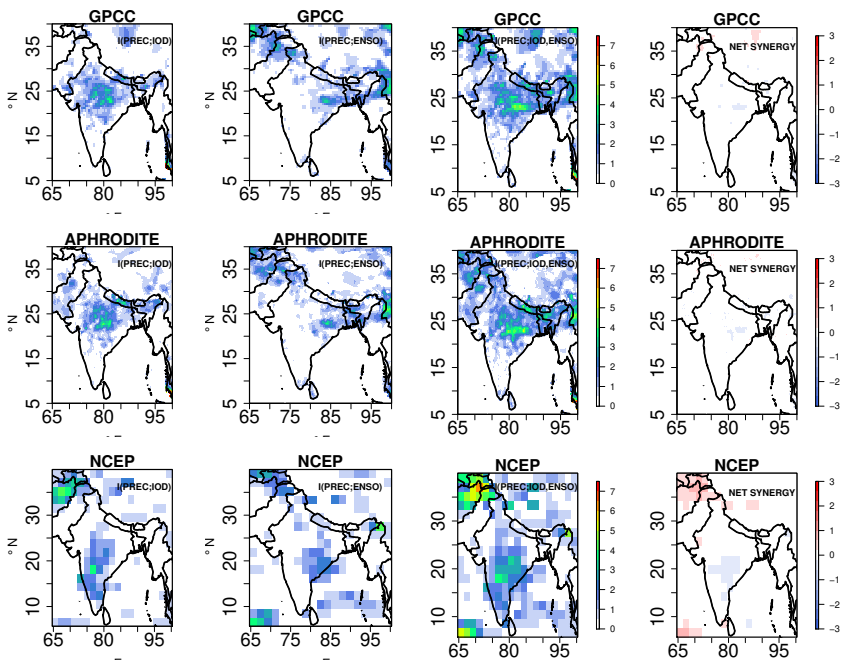

Fig. S13 Information exchange from $I(P R E C ; I O D), I(P R E C ; E N S O)$, two-source information exchange I PREC;ENSO,IOD) and NET SYNERGY $\times 10^{-2}$ nats for observational data sets GPCC, APHRODITE and NCEP reanalysis for DJFM with Linear estimator. Only significant values at $95 \%$ confidence intervals are plotted. 

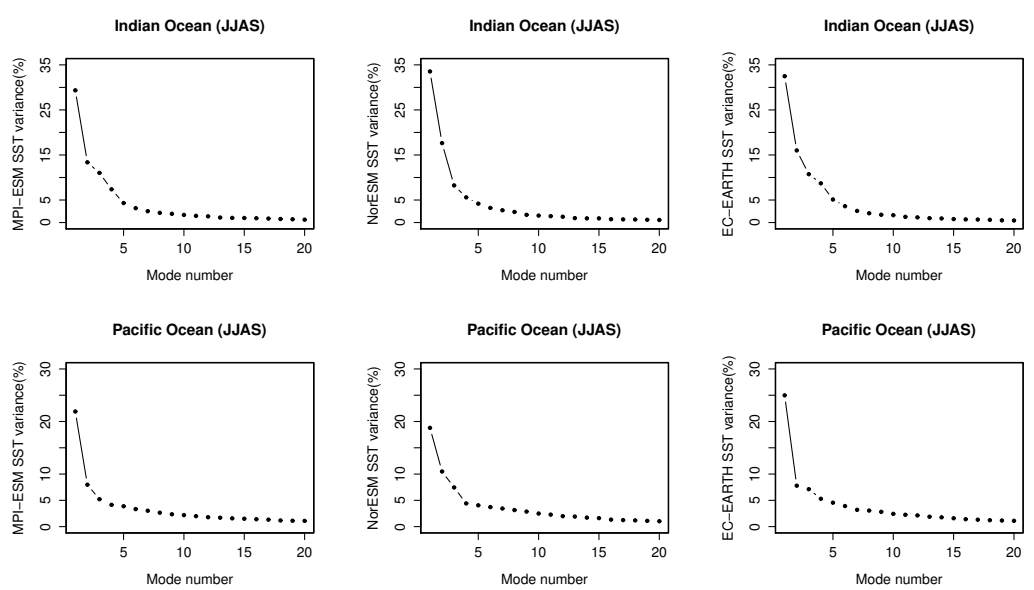

Fig. S14 Percentage of the total variance contributed by the first 20 EOFs to the total variability in Indian and Pacific Ocean SST for MPI-ESM-LR, Nor-ESM-M and EC-EARTH models for the month of JJAS (1951-2005) 

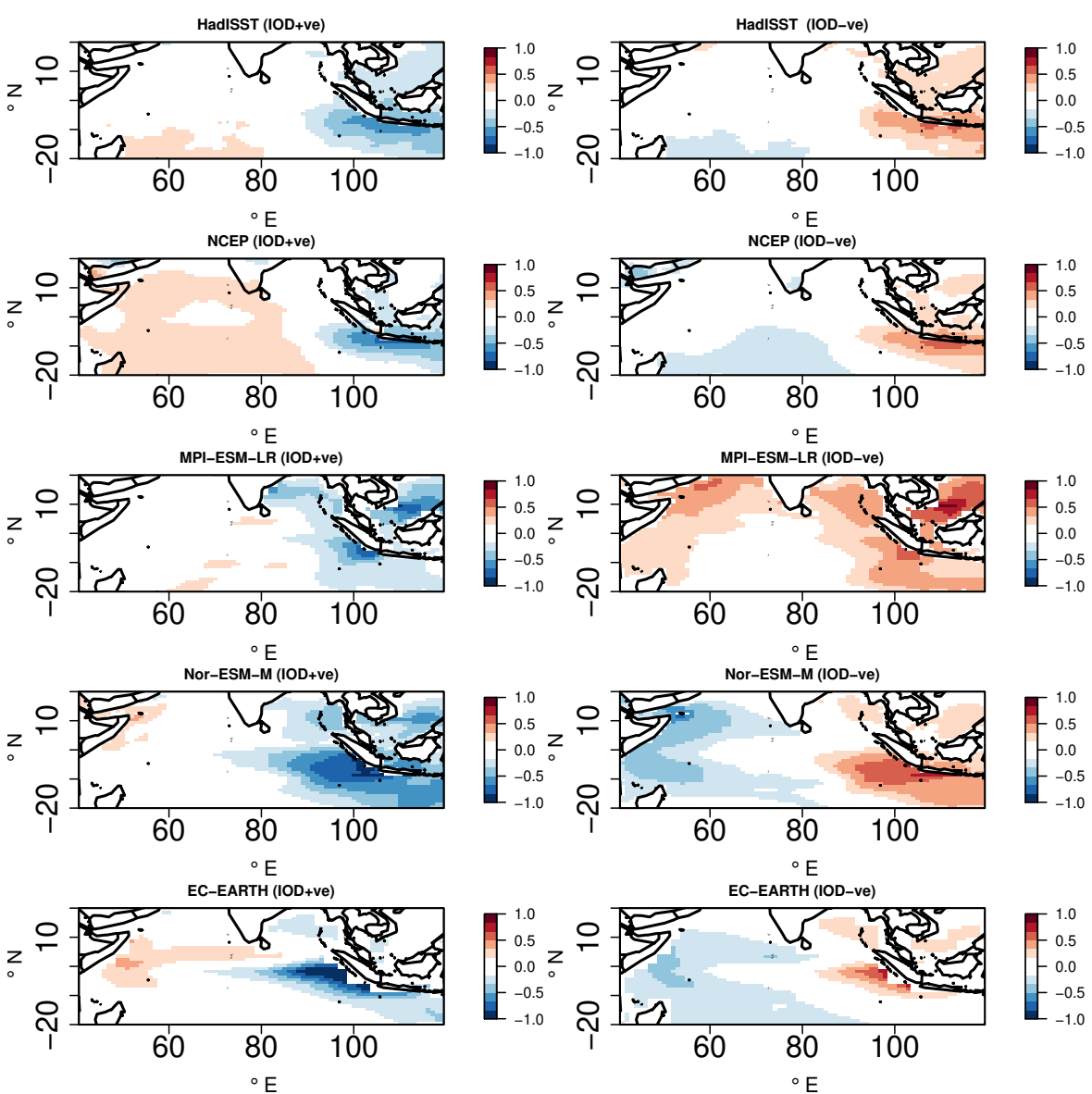

Fig. S15 SST composites for observations and GCMs for various phases of IOD events over the Indian ocean for JJAS. 


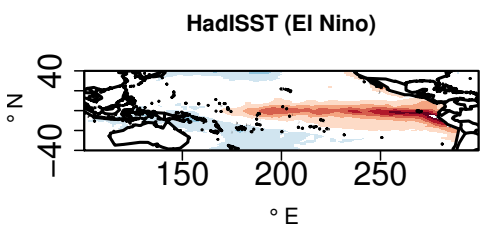

NCEP Reanalysis (EI Nino)

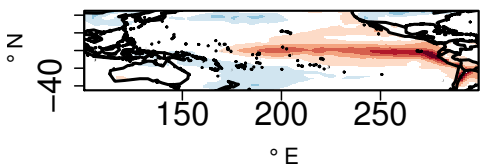

MPI-ESM-LR (EI Nino)

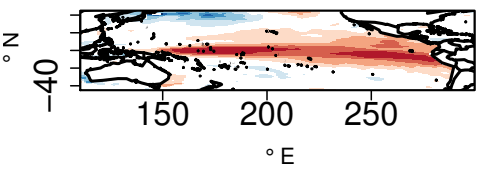

Nor-ESM-M (EI Nino)

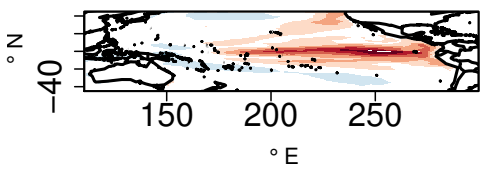

EC-EARTH (EI Nino)

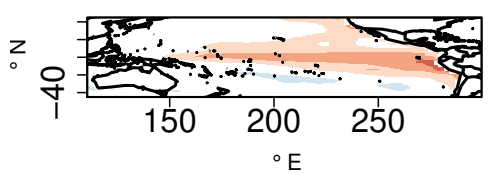

HadISST (La Nina)

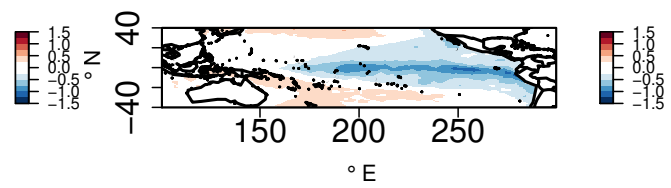

NCEP Reanalysis (La Nina)

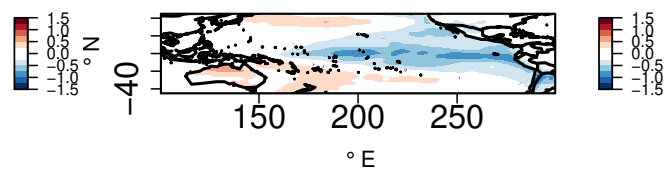

MPI-ESM-LR (La Nina)

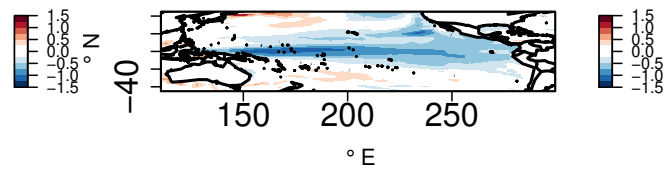

Nor-ESM-M (La Nina)

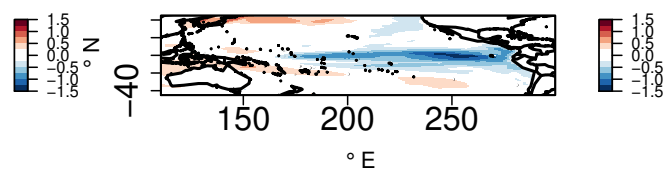

EC-EARTH (La Nina)

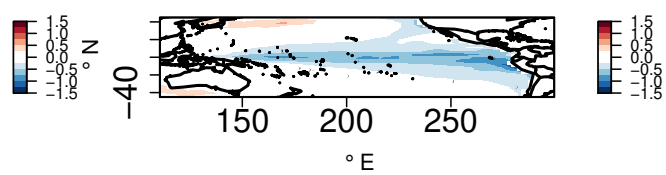

Fig. S16 SST composites for observations and GCMs for various phases of ENSO events over the Pacific ocean for JJAS. 

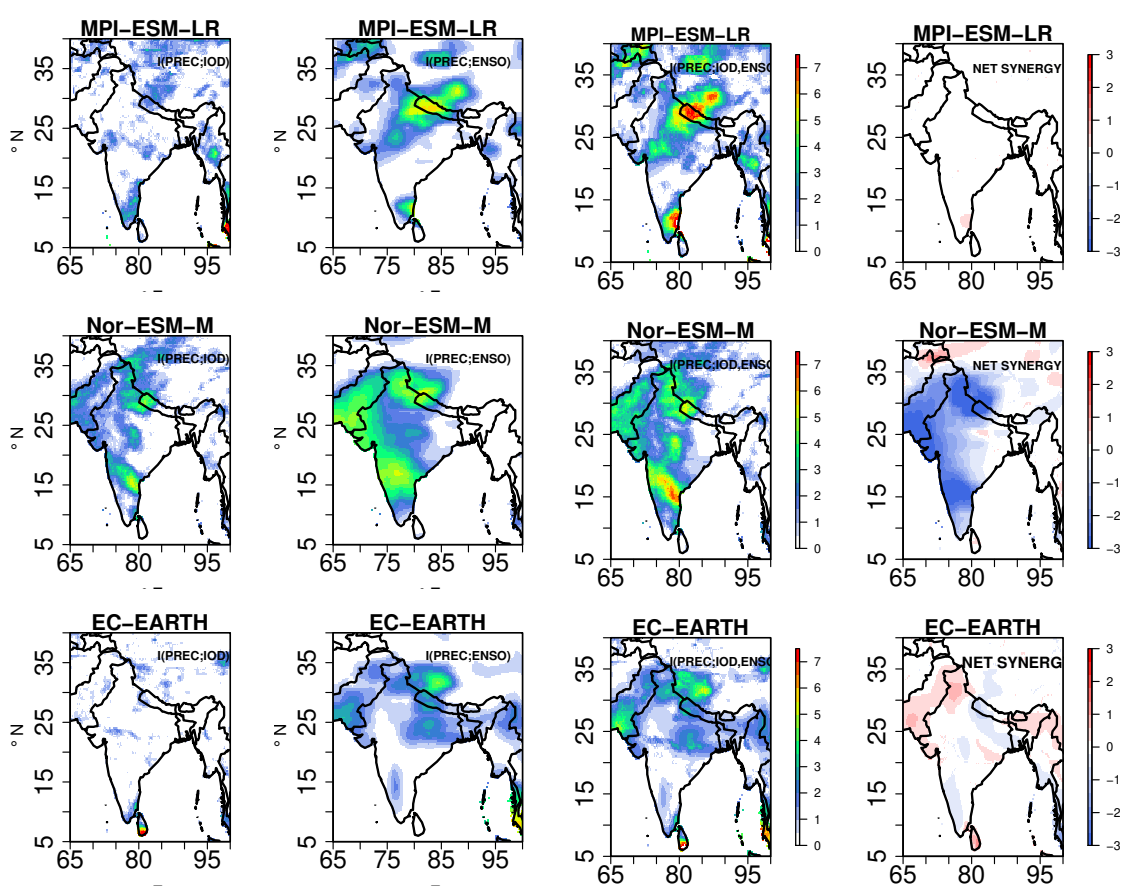

Fig. S17 Information exchange from I(PREC;IOD), I(PREC;ENSO), two-source information exchange I(PREC; ENSO,IOD) and NET SYNERGY $\times 10^{-2}$ nats for MPI-ESM-LR, Nor-ESM-M and EC-EARTH GCM models with Kraskov estimator for JJAS. Only significant values at $95 \%$ confidence intervals are plotted. 

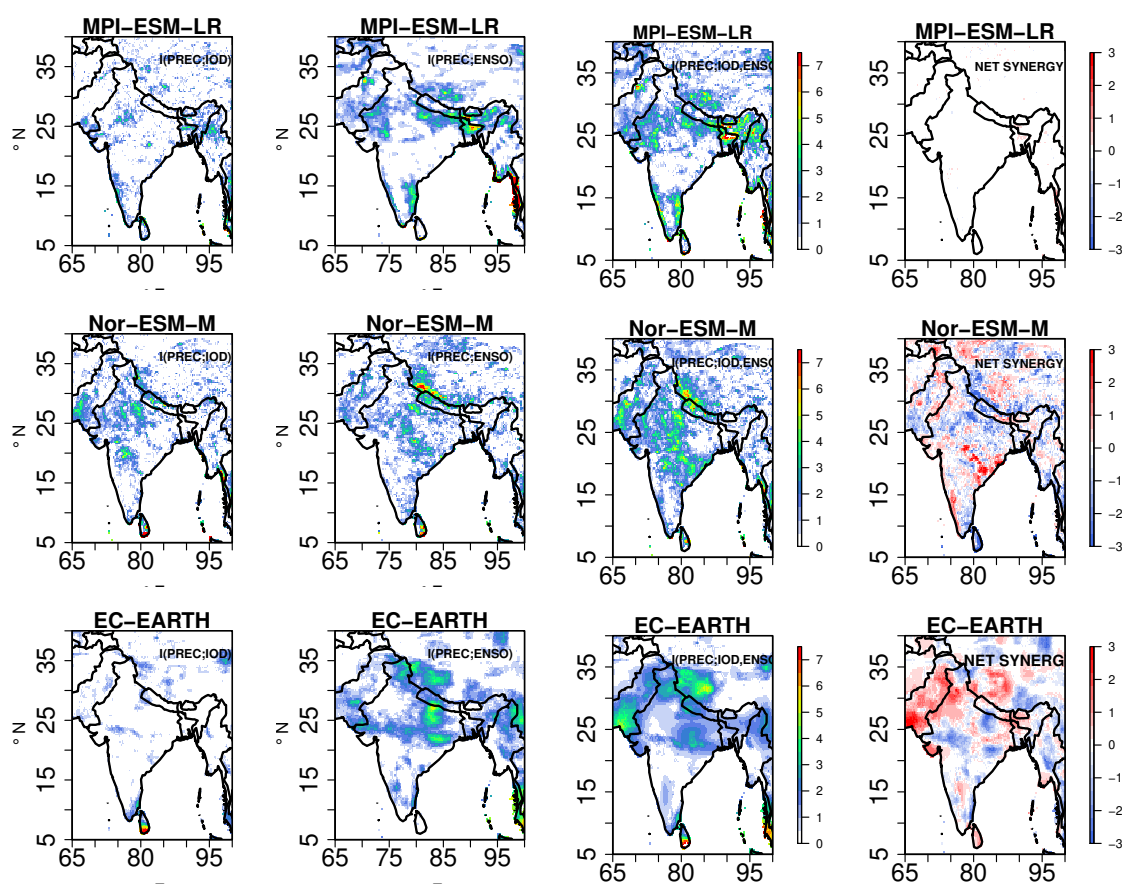

Fig. S18 Information exchange from I(PREC;IOD), I(PREC;ENSO), two-source information exchange I(PREC; ENSO,IOD) and NET SYNERGY $\times 10^{-2}$ nats for downscaled COSMO-crCLM simulations for JJAS (1951-2005) with Kraskov estimator. Only significant values at $95 \%$ confidence intervals are plotted. 

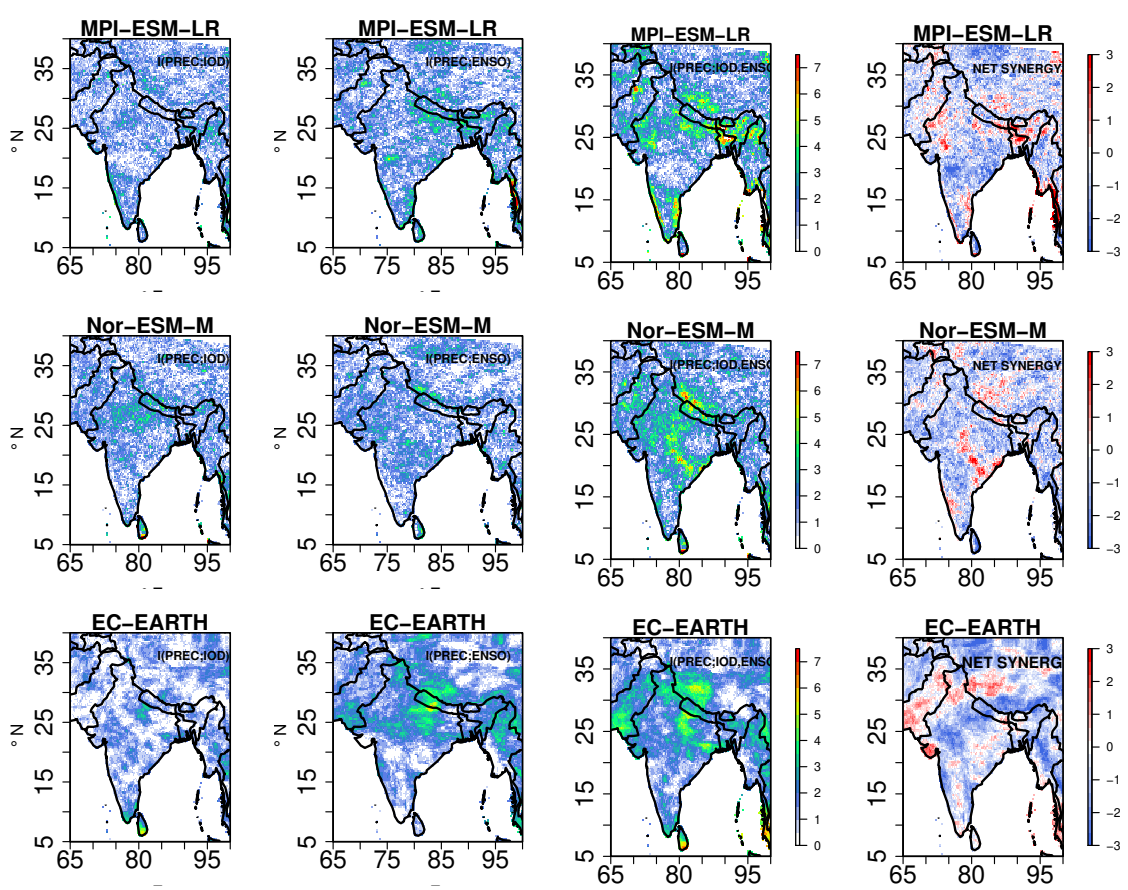

Fig. S19 Information exchange from I(PREC;IOD), I(PREC;ENSO), two-source information exchange I(PREC; ENSO,IOD) and NET SYNERGY $\times 10^{-2}$ nats for downscaled COSMO-crCLM simulations for JJAS (1951-2005) with Kernel estimator. Only significant values at $95 \%$ confidence intervals are plotted. 

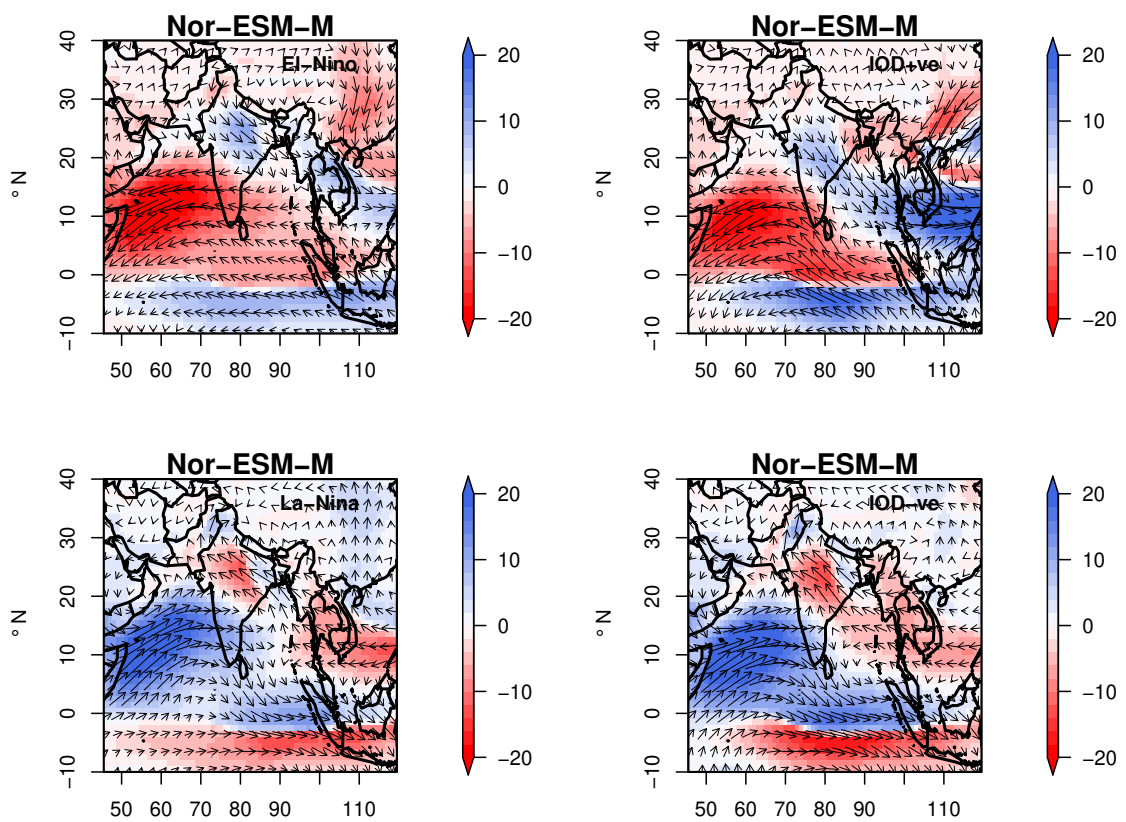

Fig. S20 Moisture flux anomalies $(\mathrm{g} / \mathrm{kg} \mathrm{m} / \mathrm{sec}$ ) over the Indian subcontinent (JJAS) for El-Niño, La-Niña, positive IOD and negative IOD events observed in Nor-ESM-M GCM for the period of 1951-2005 



Fig. S21 Moisture flux anomalies $(\mathrm{g} / \mathrm{kg} \mathrm{m} / \mathrm{sec}$ ) over the Indian subcontinent (JJAS) for El-Niño, La-Niña, positive IOD and negative IOD events observed in MPI-ESM-LR GCM for the period of 1951-2005 

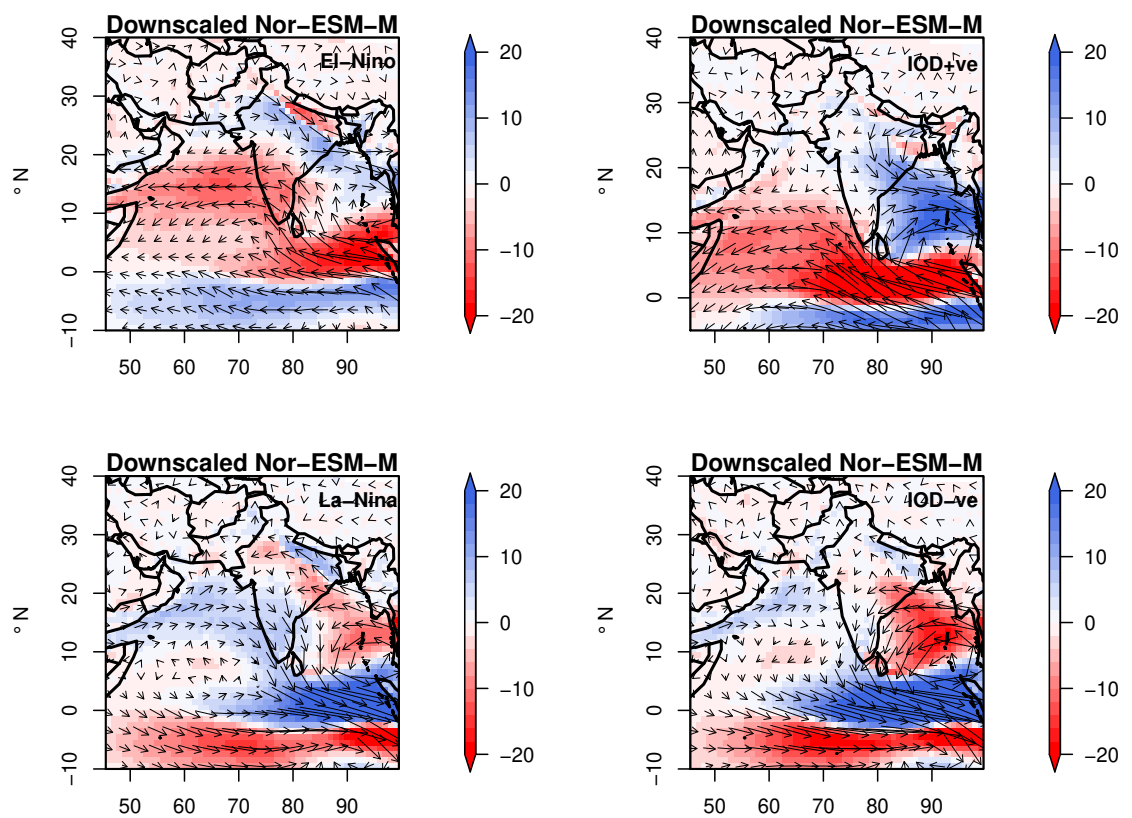

Fig. S22 Moisture flux anomalies $(\mathrm{g} / \mathrm{kg} \mathrm{m} / \mathrm{sec})$ over the Indian subcontinent (JJAS) for ElNiño, La-Niña, positive IOD and negative IOD events observed in downscaled Nor-ESM-M for the period of 1951-2005 

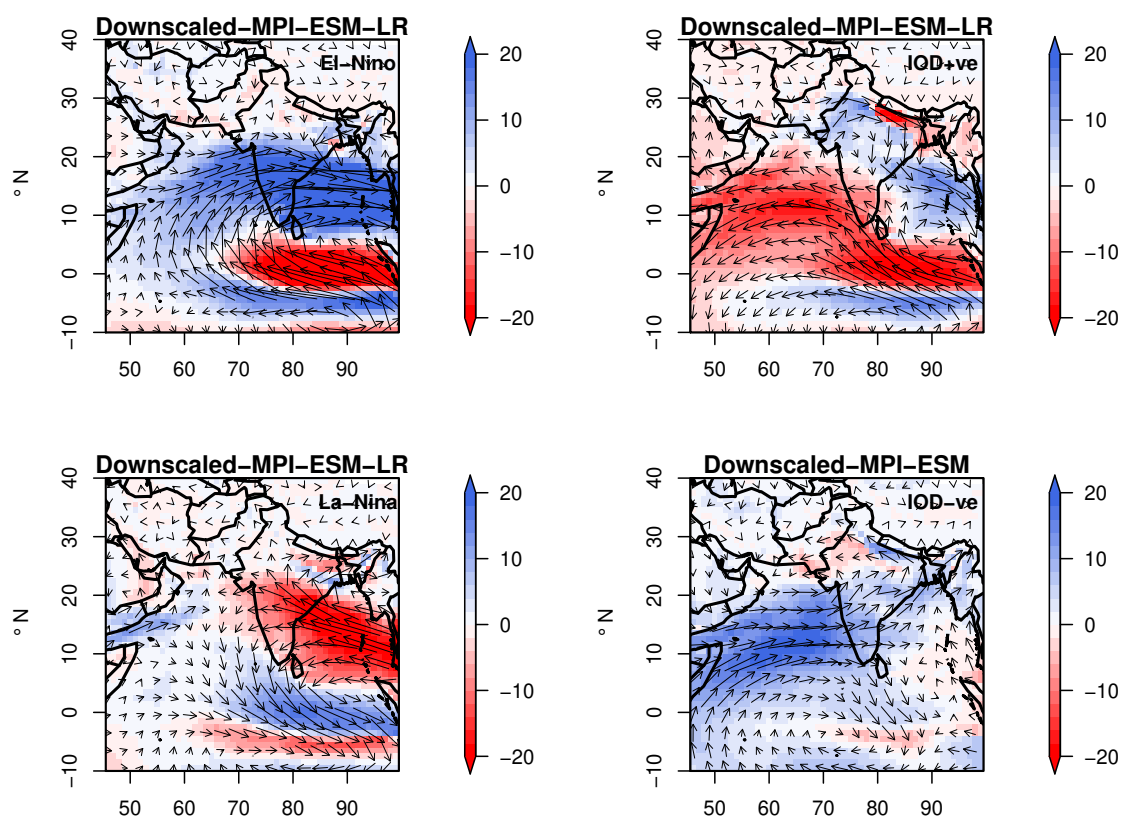

Fig. S23 Moisture flux anomalies $(\mathrm{g} / \mathrm{kg} \mathrm{m} / \mathrm{sec}$ ) over the Indian subcontinent (JJAS) for ElNiño, La-Niña, positive IOD and negative IOD events observed in downscaled MPI-ESM-LR for the period of 1960-1990 

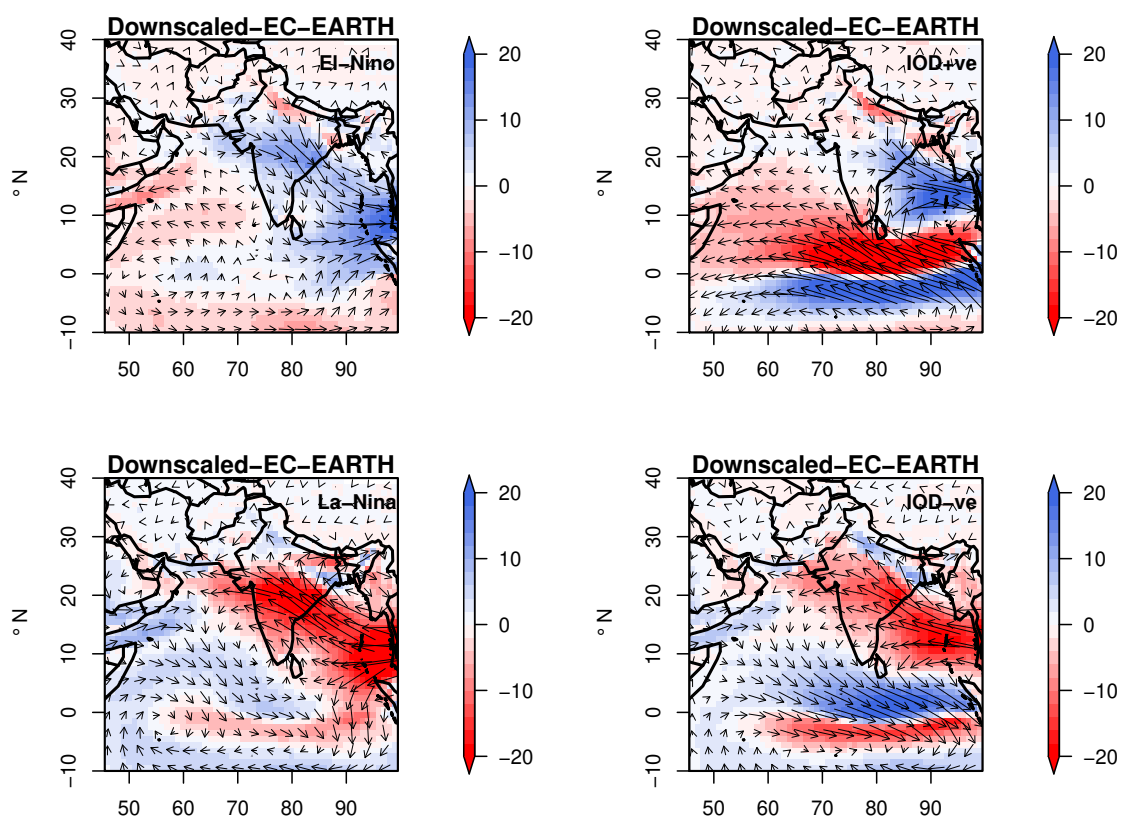

Fig. S24 Moisture flux anomalies ( $\mathrm{g} / \mathrm{kg} \mathrm{m} / \mathrm{sec}$ ) over the Indian subcontinent (JJAS) for ElNiño, La-Niña, positive IOD and negative IOD events observed in downscaled EC-EARTH for the period of 1951-2005 